\title{
Probabilistic landslide risk assessment: Case study of Bujumbura
}

\author{
Gervais Shirambere ${ }^{1, *}$, Maurice O. Nyadawa ${ }^{2}$, Jean pierre Masekanya ${ }^{3}$ and Timothy \\ Nyomboi $^{4}$ \\ ${ }^{1}$ Institute for Basic Sciences Technology and Innovation, Pan African University, Kenya \\ ${ }^{2}$ Jaramogi Oginga University of Science and Technology, Bondo, Kenya \\ ${ }^{3}$ Université du Burundi, Burundi \\ ${ }^{4}$ Moi University, Kenya
}

\begin{abstract}
A spatial probabilistic landslide risk assessment and mapping model has been applied in a data scare region. The probabilistic model is based on a physical model based on Mohr coulomb failure criterion. A Monte Carlo simulation technique is applied to field collected data. The results are integrated and a probability of landslide is obtained at each cell level. The results are compared to a prepared landslide inventory. The overall accuracy of the model is $79.69 \%$.
\end{abstract}

\section{Introduction}

The expansion of constructions and buildings in cities of developing countries creates new challenges in risk management of constructions and buildings and in environmental sustainable planning of peri-urban areas. Among the various potential risks, the landslide risk is a challenge for our study area. The Bujumbura peri-urban area has witnessed several hazards of different nature: floods, rock falls and landslides[1], [2]. In particular, landslides caused the loss of several lives, destruction of infrastructure, damage to land and loss of natural resources. Motivated by the increasing number of recorded incidents, Nibigira et al. (2015) inventoried past landslides in the western part of Burundi, which includes the Bujumbura region, and identified factors influencing the development of instabilities[3]. Kubwimana et al. (2018) developed a landslide susceptibility map using Analytic Hierarch Process (AHP) for the Kanyosha river watershed (Kubwimana et al., 2018)[4]. Nevertheless, the statistical approach proposed by Kubwimana et al. (2018) did not take in account the physical parameters linked with slope stability analysis. Several studies assessing and mapping landslide susceptibility have been conducted worldwide using two principal approaches: deterministic and statistical. For the developed deterministic models[5]-[9], the relevant factor is the factor of safety based on slope stability analysis. Slope stability analyses of landslides in deterministic models are usually performed using conventional limit equilibrium method based on the Mohr-Coulomb failure criterion. Statistical approaches [10]-[14] have also been used for landslide susceptibility assessment.

* Corresponding author: shiramberegervais@gmail.org 
Statistical approaches are more bounded to local particularities since they are always linked to a determined training dataset. The objective of this study is to develop landslide susceptibility maps using a probabilistic approach which takes in account the physical parameters of slope stability analysis and the uncertainties linked with them.

\section{Methods}

\subsection{Study area}

The study area has $31 \mathrm{~km}^{2}$ (Fig 1). It covers15 administrative districts(Fig 2). The study area belongs to the Imbo region on his western part and belongs to the Mirwa region on his eastern part. The Imbo region is a valley adjacent to steep hills and mountains of the Mirwa region. Three major watersheds cross our study area. The altitude in our study area changes from 777 to $1386 \mathrm{~m}$. The slope angle values range from $0^{\circ}$ to $57^{\circ}$. The yearly average temperature is $23^{\circ} \mathrm{C}$, and the annual precipitation is $1274 \mathrm{~mm}[15]$.

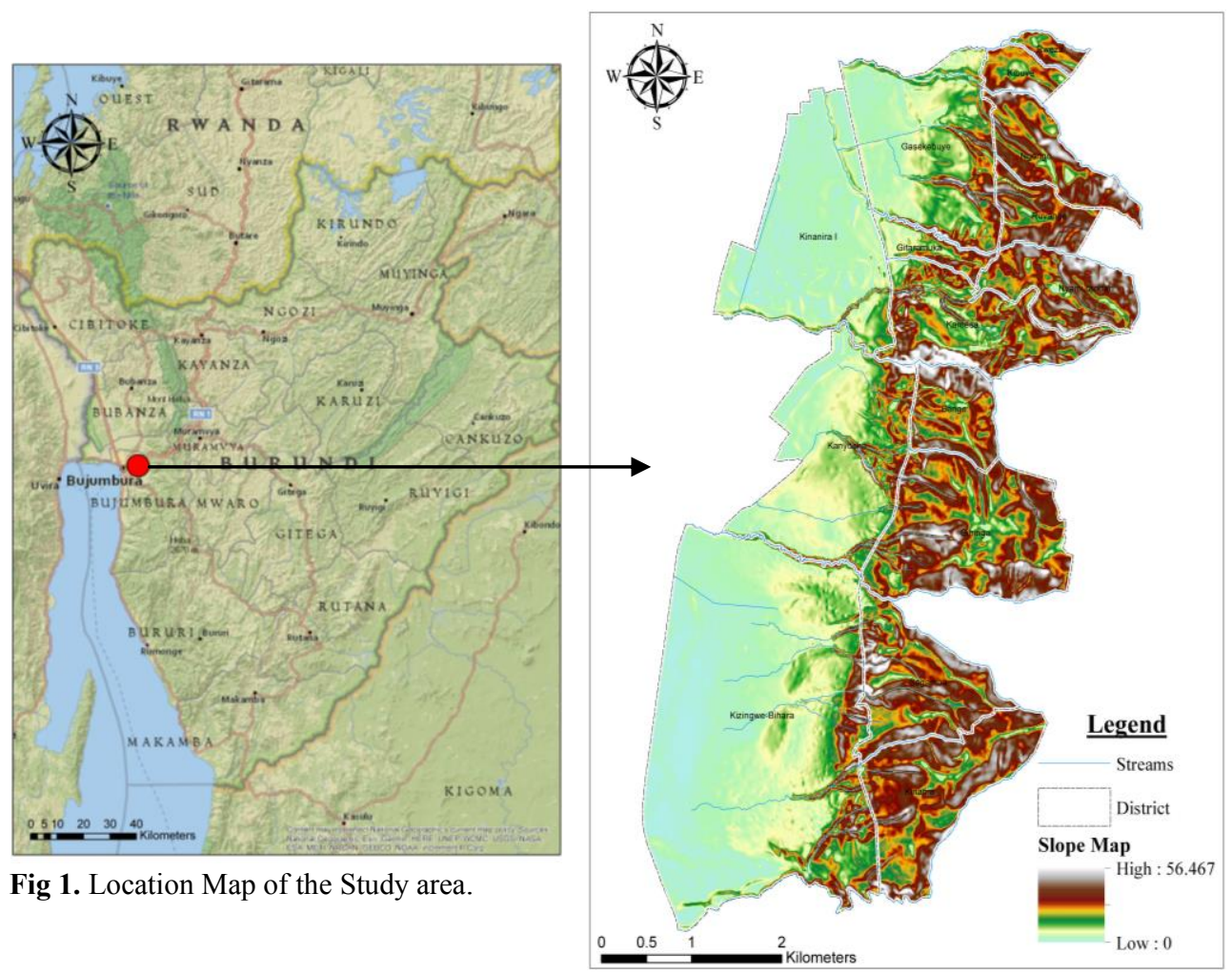

Fig 2. Study Area.

\subsection{Landslide inventory}

A landslide inventory map is required for accuracy assessment of the model results. Hence, a landslide inventory was produced using a $10 \mathrm{~m}$-resolution Digital Elevation Model (DEM), literature review, aerial ortho-images, satellite imagery (Google earth Imagery) extensive field survey. In result, a detailed and reliable inventory map with a total of 89 
landslides was created. The identified landslides were classified mainly as shallow translational slides according to classification proposed by Varnes[16].

\subsection{Physical model}

Several deterministic model have been applied in landslide hazard mapping [6], [7], [9]. Lu and Godt (2008) proposed a generalized framework for the stability of infinite slopes under steady unsaturated seepage conditions[17]. As all the deterministic models, the purpose is to determine a safety factor reflecting the stability of a considered slope. The proposed framework by $\mathrm{Lu}$ and Godt relies on the existing understanding of unsaturated-zone hydrology and considers for the first time, the contribution of suction stress in the stress analysis. The safety factor is defined by the relationship:

$$
F S=\tan \varphi^{\prime} / \tan \beta+2 c^{\prime} / \gamma H \sin 2 \beta-\left[\sigma^{s}(\tan \beta+\operatorname{cotan} \beta) \tan \varphi^{\prime}\right] / \gamma H
$$

Where $\varphi^{\prime}$ is the friction angle; $\beta$ is the slope angle; $c^{\prime}$ is the soil cohesion; $\gamma$ is the unit weight of moist soil; $H$ is the height of the soil column above the bedrock and $\sigma^{s}$ is the suction stress defined by:

$$
\sigma^{s}=\ln \left[\left(1+q / k_{s}\right) \mathrm{e}^{-\gamma \mathrm{waz}}-q / k_{s}\right] / \alpha \quad u_{a}-u_{w} \leq 0
$$

$\sigma^{s}=\left\{\ln \left[\left(1+q / k_{s}\right) \mathrm{e}^{-\gamma \mathrm{waz}}-q / k_{s}\right] / \alpha\right\} /\left\{1+\left\{-\ln \left[\left(1+q / k_{s}\right) \mathrm{e}^{-\gamma \mathrm{w \alpha z}}-q / k_{s}\right]^{n}\right\}^{(n-1) / n}\right\} u_{a}-u_{w}>0$

where $k_{s}$ is the field hydraulic conductivity; $q$ is the steady infiltration; $\gamma_{w}$ is the unit weight of water; $\alpha$ and $n$ are the empirical fitting parameters of unsaturated soils properties and the matric suction $u_{a}-u_{w}$ is defined by:

$$
u_{a}-u_{w}=-\ln \left[\left(1+q / k_{s}\right) \mathrm{e}^{-\gamma w \alpha z}-q / k_{s}\right] / \alpha
$$

The proposed slope stability takes in account soil suction. However, in the framework of our research the infiltration rate is considered equal to soil hydraulic conductivity. In this particular case the safety factor takes the form:

$$
F S=\tan \varphi^{\prime} / \tan \beta+2 c^{\prime} / \gamma H \sin 2 \beta
$$

A field survey and an extended laboratory work were conducted for the 15 administrative districts. Two hundred and twenty-five samples were collected and analyzed in laboratory. At each district level, a mean average value and a standard deviation for the concerned variables were determined from laboratory analysis(Table 1).

Table 1. Values of input variables

\begin{tabular}{|l|l|l|l|l|l|l|}
\hline \multirow{2}{*}{ District } & \multicolumn{3}{|l|}{$\begin{array}{l}\text { Friction Angle, } \\
\text { degrees }\end{array}$} & \multicolumn{2}{l|}{$\begin{array}{l}\text { Cohesion, } \\
\mathrm{kPa}\end{array}$} & \multicolumn{2}{l|}{$\begin{array}{l}\text { Soil Bulk Density, } \\
\mathrm{kN} / \mathrm{m}^{3}\end{array}$} \\
\cline { 2 - 7 } & Mean & St.Dev & Mean & St.Dev & Mean & St.Dev \\
\hline Ngongo & 34.860 & 1.040 & 22.680 & 4.461 & 14.351 & 0.103 \\
\hline Sagamba & 35.447 & 1.851 & 27.453 & 11.845 & 13.834 & 0.595 \\
\hline Kinama & 34.867 & 2.307 & 19.507 & 9.187 & 12.714 & 0.234 \\
\hline Benge & 37.680 & 3.301 & 31.600 & 10.315 & 14.478 & 0.237 \\
\hline
\end{tabular}




\begin{tabular}{|l|l|l|l|l|l|l|}
\hline Gihinga & 35.453 & 1.524 & 40.887 & 10.139 & 14.270 & 0.287 \\
\hline Ruyange & 34.840 & 2.573 & 29.460 & 13.312 & 13.051 & 0.294 \\
\hline Nyamutenderi & 39.020 & 1.236 & 14.000 & 4.879 & 12.946 & 0.268 \\
\hline Kibuye & 26.180 & 6.257 & 38.140 & 6.465 & 13.271 & 0.272 \\
\hline Rweza & 25.280 & 1.849 & 36.680 & 17.513 & 14.258 & 0.218 \\
\hline Kizingwe-Bihara & 31.453 & 5.861 & 39.720 & 21.587 & 13.604 & 0.353 \\
\hline Kanyosha & 38.200 & 4.975 & 26.120 & 19.162 & 14.140 & 0.231 \\
\hline Kamesa & 35.100 & 1.666 & 22.600 & 12.665 & 12.946 & 0.225 \\
\hline Kinanira I & 37.200 & 5.703 & 17.260 & 10.789 & 15.050 & 0.229 \\
\hline Gitaramuka & 30.540 & 6.390 & 48.320 & 22.543 & 12.770 & 0.320 \\
\hline Gasekebuye & 33.640 & 3.568 & 44.380 & 12.806 & 14.511 & 0.093 \\
\hline
\end{tabular}

The definition of the depth of soils is difficult to conduct on a regional scale. In this study a soil depth model, using a simplified approach often used in largescale regional analyses, is applied[18]. The considered model correlates soil depth to the local slope and has the form:

$$
H_{i}=H_{\max }\left[1-\left(\tan \beta_{i}-\tan \beta_{\min }\right)\left(1-H_{\min } / H_{\max }\right) /\left(\tan \beta_{\max }-\tan \beta_{\min }\right)\right]
$$

where $H_{i}$ is the computed soil depth, $H_{\max }$ and $H_{\min }$ are respectively, the maximum and the minimum soil depth measured in the area, $\beta_{i}$ is the local slope angle value and $\beta_{\max }$ and $\beta_{\min }$ are respectively maximum and minimum slope angle value measured in the area.

\subsection{Monte Carlo simulations}

In regional slope stability assessment, probabilistic methods are applied. These methods provide an accurate estimation of slope stability at a regional scale without the amount of laboratory and field work required in physical models. There are several methods such as the point estimate method [19] , first order second moment [20], [21] or Monte Carlo simulation [22] which are usually combined with a slope stability model to provide a probability of landslide instead of a safety factor. In this work a Monte Carlo simulation is applied. Soeters and Westen (1996) had given a detailed description about the application of Monte Carlo simulation method in slope stability assessment [23]. The approach includes the following steps:

1. Generate a sample of random variables using the probability distribution of $\varphi^{\prime}, c^{\prime}$ and $\gamma$ using Monte Carlo simulation method.

2. For each grid cell, compute the safety factor using the generated samples of random variables. Repeat the procedure $\mathrm{N}$ times. In most studies, $\mathrm{N}$ has a value between 50 and 2000. In our cases $\mathrm{N}$ has the value of 500. After $\mathrm{N}$ computations, probabilistic distribution curve of the slope safety factor can be obtained. By integrating the slope failure safety factor distribution curve, slope failure probability for the grid can be finally obtained.

3 . Repeat the above procedure for the entire grid and create a landslide probability map.

\section{Results}

The landslide susceptibility map obtained spatially approximates landslide inventory map prepared which validates the results obtained with our model. Landslide susceptibility map 
obtained using Monte Carlo simulations shows that $17.86 \%$ of the study area is under high probability of landslide(Fig. 3).

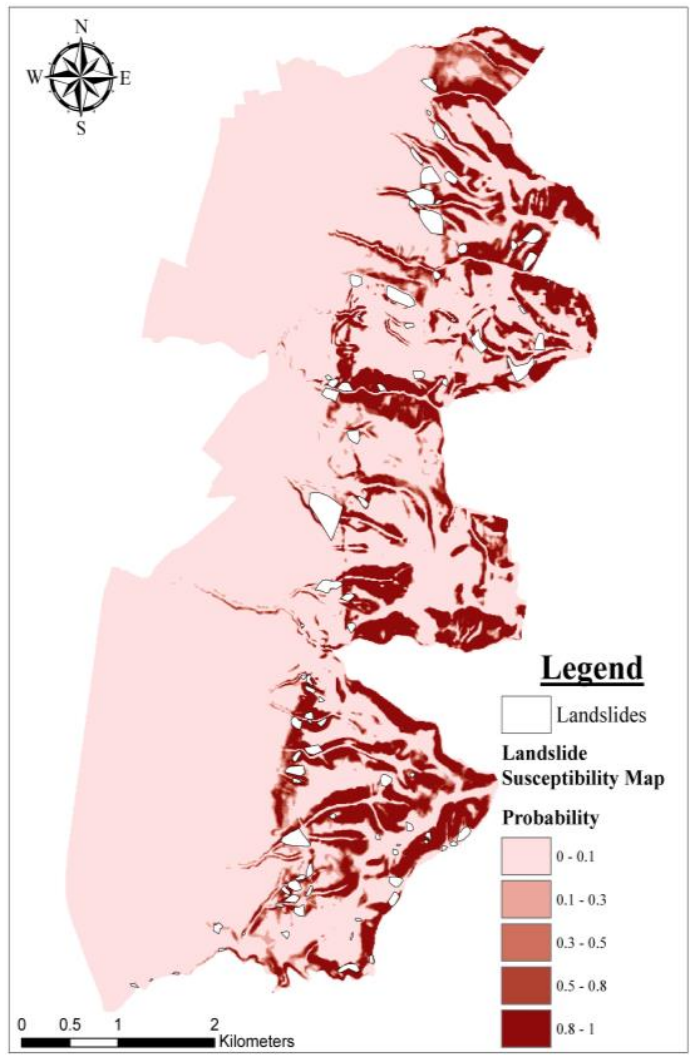

The model correctly detected the areas with low probability of landslide more accurately compared to areas with high probability of landslide. Respectively, $88.23 \%$ of true negative rate to $38.64 \%$ of true positive rate. However, the model has an overall accuracy of $79.69 \%$ hence an error rate of only $20.31 \%$ (Table 2). Around $52.11 \%$ of areas with high landslide probability have a mean friction angle of 35 degrees. This shows that there is no linear relationship between probability of landslide and the friction angle in this region. In contrast, cohesion shows direct relationship to landslide probability since $41.33 \%$ of the areas with high probability of landslide have a mean cohesion value of $19 \mathrm{kPa}$ corresponding to the lowest values of cohesion in the region. The landslide susceptibility map produced spatially approximates the slope angle map. This is due to the high contribution of the slope angle the probability of landslide.

Fig. 3. Landslide susceptibility map.

Table 2. Confusion Matrix

\begin{tabular}{|c|c|c|c|c|}
\hline & \multirow{3}{*}{ Observed } & \multicolumn{3}{|c|}{ Predicted } \\
\hline & & \multicolumn{2}{|c|}{ landslide } & \multirow{2}{*}{$\begin{array}{l}\text { Percentage } \\
\text { Correct }\end{array}$} \\
\hline & & no landslide & landslide & \\
\hline \multirow{3}{*}{ landslide } & no landslide & 31592 & 4214 & 88.23 \\
\hline & landslide & 4571 & 2879 & 38.64 \\
\hline & Overall Percentage & & & 79.69 \\
\hline
\end{tabular}

\section{Conclusion}

This research presents a complete framework for a GIS-based landslide hazard assessment and mapping in a data scarce region. The information provided forms the basis for various stakeholders in decision-making especially for risk management and environmental planning. The method proposed combines the physical parameters of slope stability and the probabilistic estimation of slope failure. The accuracy of the model was assessed using a prepared landslide inventory. The model proposed has an overall accuracy of $79.69 \%$. The results presented here showed the importance of soil cohesion in this particular region. Further study to validate and compare the model with other models need to be conducted. 


\section{References}

1. RTNB Burundi, "Les contreforts des Mirwa nécessitent une protection particulière RTNB Burundi," 19/03/2018, 2018. [Online]. Available: http://www.rtnb.bi/fr/art.php?idapi=2/2/147. [Accessed: 04-Jun-2018].

2. UNOSAT/UNOSAT, "Landslide in Rutunga, Bujumbura Rural Province, Burundi (as of 17 Apr 2015) - Burundi | ReliefWeb," 2015. [Online]. Available: https://reliefweb.int/map/burundi/landslide-rutunga-bujumbura-rural-province-burundi17-apr-2015. [Accessed: 02-Mar-2018].

3. L. Nibigira, S. Draidia, and H.-B. Havenith, "GIS-Based Landslide Susceptibility Mapping in the Great Lakes Region of Africa, Case Study of Bujumbura Burundi," in Engineering Geology for Society and Territory - Volume 2, Cham: Springer International Publishing, 2015, pp. 985-988.

4. D. Kubwimana, L. Ait Brahim, M. Bousta, O. Dewitte, A. Abdelouafi, and T. Bahaj, "Landslides susceptibility assessment using AHP method in Kanyosha watershed ( Bujumbura-Burundi ): Urbanisation and management impacts," MATEC Web Conf., vol. 149, p. 02071, 2018.

5. L. Montrasio and R. Valentino, "A model for triggering mechanisms of shallow landslides," Nat. Hazards Earth Syst. Sci., vol. 8, no. 5, pp. 1149-1159, 2008.

6. R. L. Baum, W. Z. Savage, and J. W. Godt, "TRIGRS-A Fortran Program for Transient Rainfall Infiltration and Grid-Based Regional Slope-Stability Analysis, Version 2.0.” Denver Publishing Service Center, Denver, p. 75, 2008.

7. R. T. Pack, D. G. Tarboton, and C. N. Goodwin, "SINMAP - A stability index approach to terrain stability hazard mapping," Manuel, pp. 1-75, 2003.

8. M. Anderson, D. Lloyd, and M. Kemp, "Hydrological design manual for slope stability in the Tropics," Overseas Road Note 14, 1997.

9. D. R. Montgomery and W. E. Dietrich, "A physically based model for the topographic control on shallow landsliding," Water Resour. Res., vol. 30, no. 4, pp. 1153-1171, Apr. 1994.

10.Z. Wu et al., "A comparative study on the landslide susceptibility mapping using logistic regression and statistical index models," Arab. J. Geosci., vol. 10, no. 8, 2017.

11. D. Tien Bui, Q. P. Nguyen, N. D. Hoang, and H. Klempe, "A novel fuzzy K-nearest neighbor inference model with differential evolution for spatial prediction of rainfallinduced shallow landslides in a tropical hilly area using GIS," Landslides, pp. 1-17, 21 Apr-2016.

12. H. Bourenane, M. S. Guettouche, Bouhadad, and Braham, "Landslide hazard mapping in the Constantine city, Northeast Algeria using frequency ratio, weighting factor, logistic regression, weights of evidence, and analytical hierarchy process methods," Arab. J. Geosci., vol. 9, no. 2, pp. 1-24, Feb. 2016.

13. D. Tien Bui, T. A. Tuan, H. Klempe, B. Pradhan, and I. Revhaug, "Spatial prediction models for shallow landslide hazards: a comparative assessment of the efficacy of support vector machines, artificial neural networks, kernel logistic regression, and logistic model tree," Landslides, vol. 13, no. January, pp. 361-378, Apr. 2015.

14. C. Conoscenti, M. Ciaccio, N. A. Caraballo-Arias, Á. Gómez-Gutiérrez, E. Rotigliano, and V. Agnesi, "Assessment of susceptibility to earth-flow landslide using logistic regression and multivariate adaptive regression splines: A case of the Belice River basin (western Sicily, Italy)," Geomorphology, vol. 242, pp. 49-64, Aug. 2015.

15. Direction Générale de l'Environnement, "Communication nationale sur les changements climatiques" 2005.

16. D. J. Varnes, "Slope Movement Types and Processes," Transp. Res. Board Spec. Rep., no. 176, pp. 11-33, 1978. 
17. N. Lu and J. Godt, "Infinite slope stability under steady unsaturated seepage conditions," Water Resour. Res., vol. 44, no. 11, p. n/a-n/a, Nov. 2008.

18. G. M. Saulnier, K. Beven, and C. Obled, "Including spatially variable effective soil depths in TOPMODEL," J. Hydrol., vol. 202, no. 1-4, pp. 158-172, 1997.

19. T. L. Tsai, P. Y. Tsai, and P. J. Yang, "Probabilistic modeling of rainfall-induced shallow landslide using a point-estimate method," Environ. Earth Sci., vol. 73, no. 8, pp. 4109-4117, 2015.

20. E. Arnone, Y. G. Dialynas, L. V. Noto, and R. L. Bras, "Parameter Uncertainty in Shallow Rainfall-triggered Landslide Modeling at Basin Scale: A Probabilistic Approach," Procedia Earth Planet. Sci., vol. 9, pp. 101-111, 2014.

21. W. C. Haneberg, "A Rational Probabilistic Method for Spatially Distributed Landslide Hazard Assessment," Environ. Eng. Geosci., vol. 10, no. 1, pp. 27-43, 2004.

22. G. Zhou, T. Esaki, Y. Mitani, M. Xie, and J. Mori, "Spatial probabilistic modeling of slope failure using an integrated GIS Monte Carlo simulation approach," Eng. Geol., vol. 68, no. 3-4, pp. 373-386, 2003.

23. C. J. Van Westen, "Slope instability Recognition, analysis and zonation," no. December, 2016. 